\title{
Transesophageal echocardiography measurements of aortic annulus diameter using biplane mode in patients undergoing transcatheter aortic valve implantation
}

Kambiz Shahgaldi ${ }^{1,2^{*}}$, Cristina da Silva ${ }^{1,2}$, Magnus Bäck ${ }^{1}$, Andreas Rück', Aristomenis Manouras ${ }^{1,2}$ and Anders Sahlén ${ }^{1}$

\begin{abstract}
Background: Aortic stenosis (AS) is a relevant common valve disorder. Severe AS and symptoms and/or left ventricular dysfunction (EF $<50 \%$ ) have the indication for aortic valve replacement (AVR). Majority of the patients with AS are elderly often with co-morbidities and generally have high preoperative risk. Transcatheter aortic valve implantation (TAVI) is offered in this group. Four different sizes of Corevalve prosthesis are available. Correct measurement of aortic size prior to TAVI is of great important to choose the right prosthesis size to avoid among others paravalvular leak or prosthesis patient mismatch.

Aim of the study is to assess the aortic annulus diameter in patients undergoing TAVI by biplane (BP) mode using transesophageal echocardiography (TEE) and compare it to two-dimensional (2D) transthoracic echocardiography (TTE) and 2DTEE using three-dimensional (3D) TEE as reference method.
\end{abstract}

Methods: The study population consisted of 50 patients retrospectively (24 men and 26 women, mean age $85 \pm 8$ years of age) who all had undergone echocardiography examination prior to TAVI.

Results: The mean aortic annulus diameter was $20.4 \pm 2.2 \mathrm{~mm}$ with TTE, $22.3 \pm 2.5 \mathrm{~mm}$ with $2 \mathrm{DTEE}, 22.9 \pm 1.9 \mathrm{~mm}$ with BP-mode and $23.1 \pm 1.9 \mathrm{~mm}$ with 3DTEE. TTE underestimated the mean aortic annulus diameter in comparison to transesophageal imaging modalities $(p<0.001)$. Using 3DTEE, $2 \%$ of patients were unsuitable for TAVI due to a too-small AoA $(n=1)$. This figure was similar with BP $(4 \%, n=2 ; p=1.00)$ but considerably larger with 2DTTE (36\%, $n=18 ; p<0.001)$ and 2DTEE $(12 \%, n=6 ; p=0.06)$. There was a strong correlation between BP-mode and 3DTEE for assessment of aortic annulus diameter ( $r$-value 0.88 ) with small mean difference $(-0.2 \pm 0.9 \mathrm{~mm}$ ) whereas the other modalities showed larger 95\% confidence interval and modest correlation (2DTTE vs. 3DTEE, -6.3 to $0.9 \mathrm{~mm}, \mathrm{r}=0.64$ and 2DTEE vs. 3DTEE, -4.8 to $3.2 \mathrm{~mm}, \mathrm{r}=0.61$ ).

Conclusion: A multi-dimensional method is preferred to assess aortic annulus diameter in TAVI patients since there is risk of underestimation using single plane. Biplane mode is the method of choice in view of speedy post-processing with no need for expensive dedicated software. Lastly, single plane methods lead to misclassification of patients as unsuitable for TAVI. This may be of major clinical importance.

Keywords: Transcatheter aortic valve implantation, Transesophageal echocardiography, Aortic annulus, Biplanemode, Three-dimensional transesophageal echocardiography

\footnotetext{
* Correspondence: kambiz.shahgaldi@karolinska.se

'Karolinska Institutet, Department of Cardiology, Karolinska University Hospital, Huddinge 141 86, Stockholm, Sweden

${ }^{2}$ School of Technology and Health, Royal Institute of Technology, Huddinge

14152 , Sweden
}

\section{Biomed Central}

(c) 2013 Shahgaldi et al.; licensee BioMed Central Ltd. This is an Open Access article distributed under the terms of the Creative Commons Attribution License (http://creativecommons.org/licenses/by/2.0), which permits unrestricted use, distribution, and reproduction in any medium, provided the original work is properly cited. 


\section{Background}

Aortic stenosis (AS) affects nearly $5 \%$ of patients $>75$ years of age [1,2]. Aortic valve replacement (AVR) is indicated in severe AS with symptoms or left ventricular (LV) dysfunction, as the prognosis is otherwise poor [3]. Transcatheter aortic valve implantation (TAVI) is a relatively new procedure which is increasingly being offered in elderly or high-risk patients with AS that are considered unsuitable for open heart surgery due to co morbidities [4-6]. Accurate pre-operative evaluation of aortic annulus (AoA) diameter is important as it determines the selection of prosthesis size. Implantation of an appropriately-sized prosthesis enables the procedure to be performed with a smaller risk of serious complications including aortic root damage, AV-block, prosthesis embolization or paravalvular regurgitation [7]. The most common modalities for measuring AoA are transthoracic echocardiography (TTE), transesophageal echocardiography (TEE) and coronary angiography. However, as these are two-dimensional (2D) methods, the AoA is measured in only one image plane. This introduces a risk that the maximal diameter is underestimated, with obvious and potentially serious clinical consequences as illustrated by a post-TAVI incidence of severe PPM of approximately $2-6 \%[8,9]$.

To date, there is no established gold standard technique for measuring AoA prior to TAVI. Recent studies have compared TTE, 2DTEE, three-dimensional (3D) TEE, multislice-computed tomography (MSCT) and magnetic resonance imaging (MRI) for the determination of AoA in this group [10-12]. MSCT has been suggested for improved pre-procedural annular measurement and prosthesis sizing [13-16]. 3DTEE has been demonstrated to measure AoA size accurately when compared to dual-source CT and intra-operative measurements, as it allows the maximal diameter of the annulus to be directly visualized in short axis view after careful alignment [12,17]. A recent study demonstrated that AoA measured by $3 \mathrm{DTEE}$ is larger than with 2DTEE and concluded that this had considerable impact on choice of prosthesis size [18].

2DTTE is the first method of choice according to the recent European Association of Echocardiography and American Society of Echocardiography (EAE/ASE) recommendations for the use of echocardiography in transcatheter intervention [19]. If measurements are close to critical cut-offs for valve size selection, or if there is difficulty in measuring annulus size due to calcification, the authors suggest that TEE and/or 3DTEE may be necessary. While 3DTEE has emerged as a promising technique, this technique enables the annulus to be measured during post-processing at a dedicated work station. On the contrary, biplane (BP) mode is an attractive complement to $2 \mathrm{D}$ imaging as it enables multi-planar imaging to be performed, and AoA measurements taken, on-line. In BP-mode, two simultaneous views of the annulus are recorded simultaneous. As previous research in this field has not formally shown the validity of BP-mode in this setting, and as prosthesis sizing is essential in TAVI patients, we wished to investigate this important methodological question.

We tested the hypothesis that measurement of AoA dimension using BP-mode in patients with severe AS referred for TAVI results in more accurate and reproducible measurements compared to $2 \mathrm{D}$ techniques, using 3DTEE as reference method.

\section{Material and methods Patient population}

Fifty patients were studied retrospectively with severe AS referred to our centre for TAVI (Medtronic-CoreValve Inc., Minneapolis, MN) and who had undergone 2DTTE, 2DTEE, BP-mode and 3DTEE acquisition, were included in this retrospective study. All examinations were clinically indicated as pre-TAVI work-up. The study complied with the declaration of Helsinki.

\section{D transthoracic echocardiography}

All patients underwent complete echocardiography examination in the left lateral decubitus position using commercially available ultrasound system (iE33, Philips, Andover, Massachusetts, USA) with a 1-5 MHz transducer (S5-1). Analyses were performed at a dedicated workstation using a commercially available software package (EchoPAC, GE, Horten, Norway). The severity of AS was assessed in agreement with EAE/ASE recommendations [20] and the degree of aortic regurgitation was assessed according to current guidelines [21]. All measurements of AoA were taken during systole and recorded as an average from 3 beats. As shown in Figure 1A, AoA was recorded as the inner edge to inner edge distance measured from the junction of the aortic right coronary cups with the septal endocardium to the junction of the non-coronary cups with the mitral valve posteriorly. Annular calcification was included [15,20,22]. During TTE, AoA was measured in zoom mode in the parasternal long-axis view. All measurements were performed blinded from each other by two experienced investigators.

\section{D and 3D transesophageal echocardiography}

The Philips iE33 system (Philips, Andover, Massachusetts, USA) was used with a TEE (X7-2t) transducer allowing both $2 \mathrm{D}$ and 3DTEE images. This matrix array transducer provides high-resolution real-time 3D imaging. AoA was acquired in mid esophageal position using an image plane between $120^{\circ}-150^{\circ}$. 


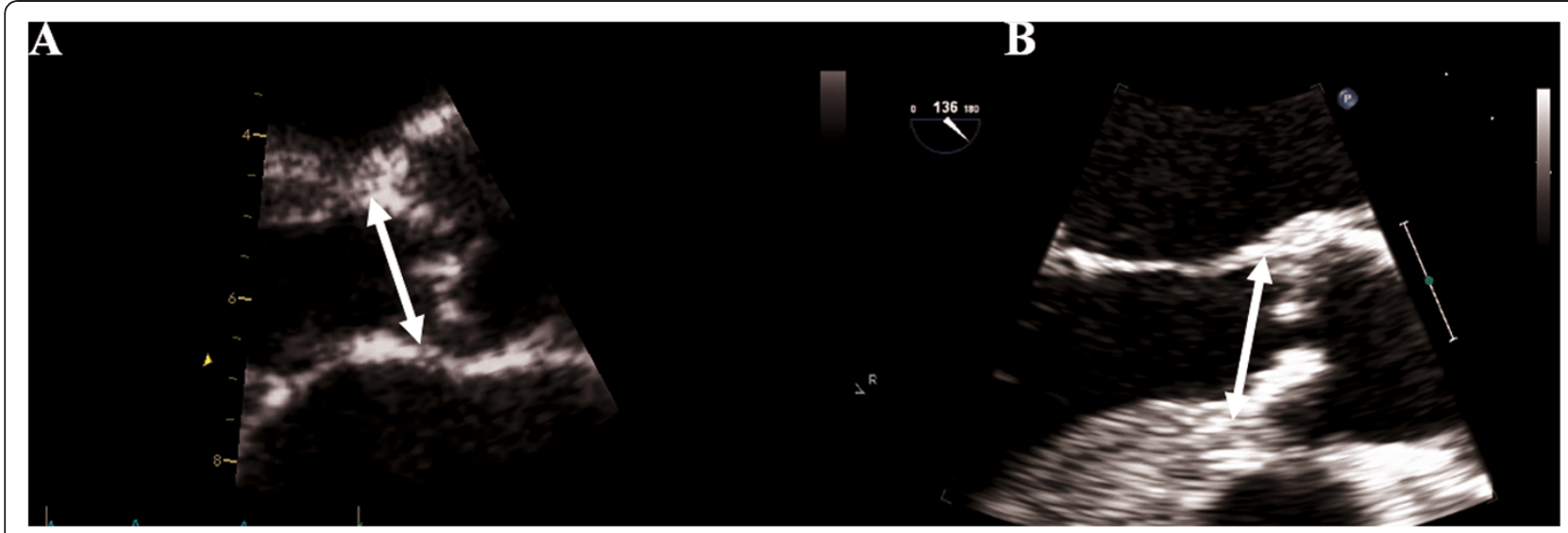

Figure $1 \mathrm{~A}$ and B. Aortic annulus measurements performed by transthoracic and transesophageal echocardiography. Aortic annulus dimension is indicated by the arrow.

During 2DTEE image acquisition, every effort was made to ensure that the largest annulus diameter was obtained using zoom mode. Measurements were performed in the same manner as with 2DTTE (Figure 1B).

When acquiring aortic valve using 3D technique, the probe was positioned in the mid esophageal position between $120^{\circ}-150^{\circ}$, and compression, gain and depth settings were optimized using a zoomed image. Real-time 3D imaging of a pyramidal volume of the aortic valve was obtained (average temporal resolution $20 \pm 3$ frames/ sec). All images were acquired during 3 cardiac cycles. The gathered 3D images of aortic valve were analyzed off-line (Q-LAB cardiac 3DQ, Philips, Andover, Massachusetts, USA). Using the multiplanar reformation (MPR) mode, standard short-axis views of the aortic valve were generated at the insertion of the cusps in systole. A sagittal view of the aortic annulus was obtained by placing a cut plane across a short-axis view centered on the ascending aorta, enabling the sagittal annular diameter to be recorded (Figure 2).

Imaging of the aortic valve in BP-mode was performed in a short axis view of the aorta. By positioning the $\mathrm{X}$ plane across the aorta, the valve was visualized in longaxis $\left(90^{\circ}\right.$ from short-axis view). Great care was taken to place the X-plane (cursor) in the midposition in the short-axis aortic valve view (Figure 3). Mean frame rate during acquisition of BP-mode images was $43 \pm 11$ frames/sec.

\section{Statistical analysis}

All statistical analyses were performed with IBM SPSS Statistics version 18.0 (IBM Corp., Armonk, NY, U.S.A.). Measurements of AoA obtained by different echocardiographic techniques were compared using Pearson's correlation coefficient ( $r$ ) and Bland-Altman analysis [23]. Comparison between variables was performed using analysis of variance (ANOVA). Suitability for TAVI
(AoA $>$ or $<20 \mathrm{~mm}$ ) was tested between methods using McNemar's test for proportions for paired data. In a subgroup of 20 patients, the measurements of AoA size were repeated by a separate, independent investigator in order to assess inter-observer variability. Observer variability was analyzed using the following formula: $\left(\mathrm{SD}_{\text {diff }} \times 100 \%\right) /$ total mean $\times \sqrt{ } 2$, where $\mathrm{SD}_{\text {diff }}$ is the SD of differences between measurements [24]. Statistical significance was considered present for $\mathrm{p}<0.05$. Continuous variables are expressed as mean $\pm \mathrm{SD}$.

\section{Results}

No patients were excluded from the analysis due to poor image quality. The 3DTEE measurement of AoA

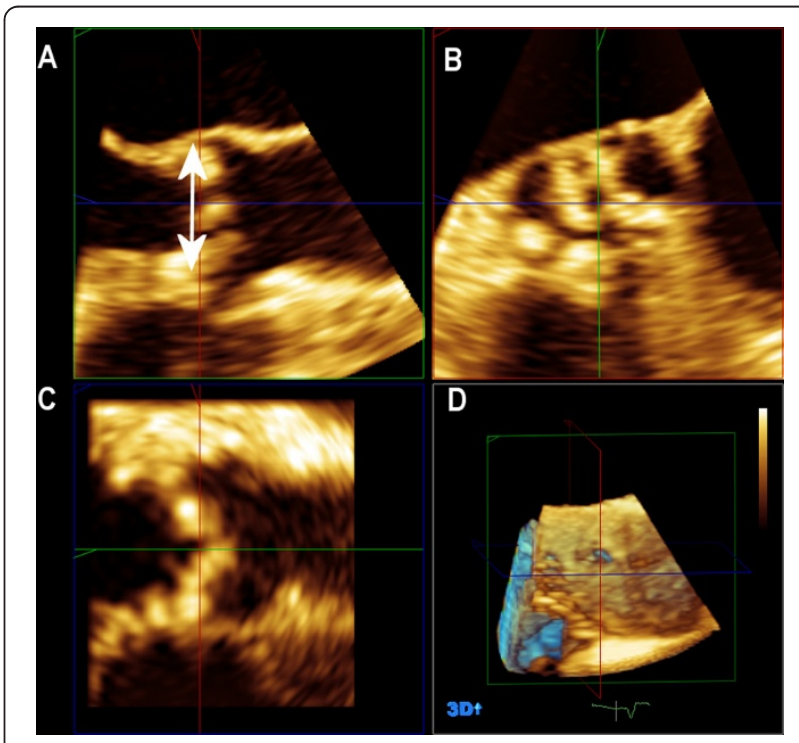

Figure 2 Reconstruction of the three-dimensional transesophageal echocardiography in 3-chamber view $(A, D)$ and measurement of aortic annulus diameter $(A)$. The coronal and the short axis views of the aortic valve are shown (B, C). 


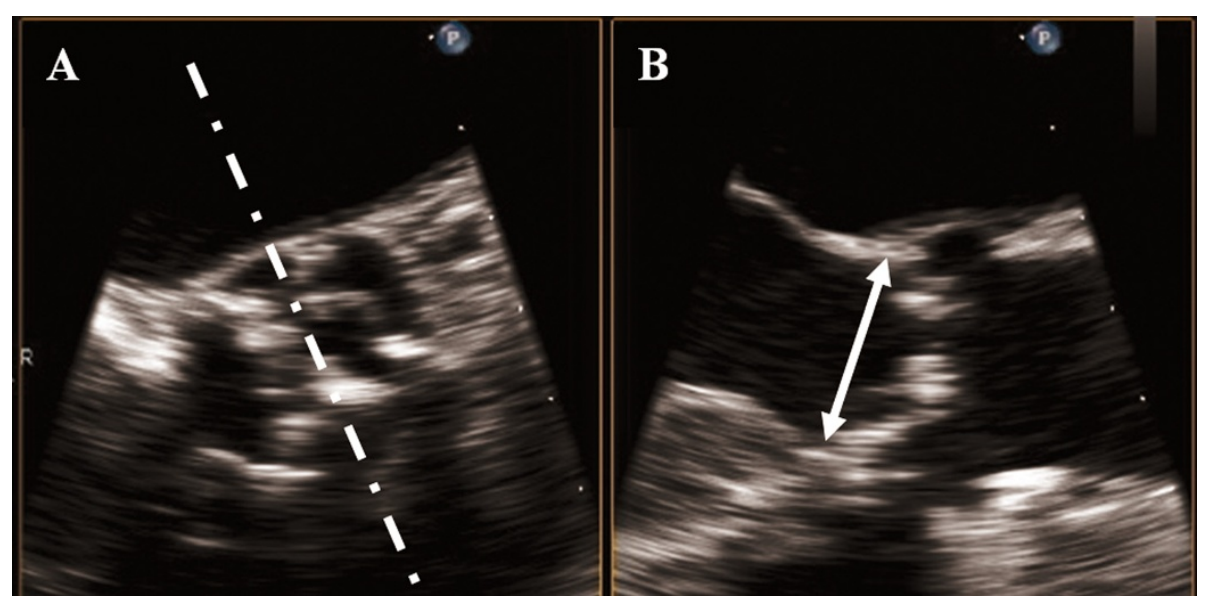

Figure 3 Visualization of aortic valve by biplane-mode in short axis view (A) and the corresponding long axis view (B). Every effort is made to place the cursor across the largest annulus diameter.

dimension was the method used for the selection of prosthesis size.

Basic patient characteristics of the study population are shown in Table 1. Mean AoA dimension obtained by different imaging modalities is presented in Table 2 . As shown, significantly smaller measurements were obtained by 2DTTE than with other imaging modalities ( $p<0.0001)$. We found no statistically significant difference in AoA size between 2DTEE vs. BP-mode vs. RT3DE. However, limits of agreement between 2DTEE and other 3D imaging modalities for assessment of AoA dimension were relatively wide (2DTEE vs. BPmode $-0.6 \pm 1.7 \mathrm{~mm}$; $2 \mathrm{DTEE}$ vs. $3 \mathrm{DTEE}-0.8 \pm 2.0$ $\mathrm{mm}$; Table 3 ). On the other hand, not only the correlation but also the agreement between BP-mode and 3DTEE for AoA size determination were high as illustrated in Bland-Altman analysis (mean difference $-0.2 \pm$ $0.9 \mathrm{~mm}, \mathrm{r}=0.88$; Table 3).

There was evidence of misclassification the AoA in a subgroup of patients: the proportion regarded as having

Table 1 Basic patients characteristics $(n=50)$

\begin{tabular}{|c|c|}
\hline Variable & Value \\
\hline Age (years) & $85 \pm 8$ \\
\hline Male/female (n) & $24 / 26$ \\
\hline Body surface area $\left(\mathrm{m}^{2}\right)$ & $2.2 \pm 0.6$ \\
\hline LV Ejection Fraction (\%) & $55 \pm 9$ \\
\hline Heart rate (beats/min) & $76 \pm 13$ \\
\hline Peak jet velocity (m/s) & $4.3 \pm 0.6$ \\
\hline Mean gradient (mmHg) & $50 \pm 16$ \\
\hline Aortic valve area $\left(\mathrm{cm}^{2}\right)$ & $0.7 \pm 0.2$ \\
\hline Index aortic valve area $\left(\mathrm{cm}^{2} / \mathrm{m}^{2}\right)$ & $0.4 \pm 0.1$ \\
\hline
\end{tabular}

LV, left ventricle. a too-small annulus to undergo TAVI was $2 \%$ with 3DTEE $(\mathrm{n}=1)$. This figure was similar with BP-mode $(4 \%, \mathrm{n}=2$; $\mathrm{p}=1.00)$ but considerably higher with both 2DTTE (36\%, $\mathrm{n}=18 ; \mathrm{p}<0.001)$ and 2DTEE $(12 \%, \mathrm{n}=6 ; \mathrm{p}=0.06)$, indicating a large subgroup of patients were wrongly considered unsuitable for TAVI with 2DTTE.

\section{Variability}

Interobserver variability was assessed in a subgroup of 20 patients. Interobserver reproducibility for the different imaging modalities were as follow: $3.2 \%$ for 3DTEE, $4.7 \%$ for 2DTTE, $4.0 \%$ for 2DTEE and $3.6 \%$ for BPmode. Statistical analysis showed significant differences regarding reproducibility between 2DTTE and 2DTEE in comparison to BP-mode and 3DTEE $(\mathrm{p}<0.001)$.

\section{Discussion}

A growing group of patients are offered AVR today in whom open heart surgery has previously been impossible due to co-morbidities and/or advanced age, following the advent of TAVI. It is crucial that correct measurements of AoA are obtained as implantation of a poorly matched prosthesis can have severe or even fatal

Table 2 Aortic annulus measurements assessed by different echocardiographic modalities

\begin{tabular}{ll}
\hline Modality & Aortic annulus diameter $(\mathbf{m m})$ \\
\hline 2DTTE & $20.4 \pm 2.2^{*}$ \\
2DTEE & $22.3 \pm 2.5$ \\
BP-mode & $22.9 \pm 1.9$ \\
3DTEE & $23.1 \pm 1.9$
\end{tabular}

${ }^{*} \mathrm{p}<0.0001$ vs. 2D-TEE, BP-mode and RT3DE. 2D denotes two-dimensional; 3D, three-dimensional; TTE, transthoracic echocardiography; TEE, transesophageal echocardiography; BP, biplane. 
Table 3 Agreement between different echocardiographic modalities

\begin{tabular}{|c|c|c|c|c|}
\hline & Mean difference \pm SD & Limits of agreement & r-value & p-value* \\
\hline TTE-2DTEE & $-2.0 \pm 2.1$ & -6.2 to 2.2 & 0.60 & $<0.05$ \\
\hline TTE-BP & $-2.5 \pm 1.9$ & -6.3 to 1.3 & 0.58 & $<0.05$ \\
\hline TTE-3DTEE & $-2.7 \pm 1.8$ & -6.3 to 0.9 & 0.64 & $<0.05$ \\
\hline 2DTEE-BP & $-0.6 \pm 1.7$ & -4.0 to 2.8 & 0.72 & $<0.05$ \\
\hline 2DTEE-3D & $-0.8 \pm 2.0$ & -4.8 to 3.2 & 0.62 & $<0.05$ \\
\hline BP-3DTEE & $-0.2 \pm 0.9$ & -2.0 to 1.6 & 0.88 & $<0.05$ \\
\hline
\end{tabular}

SD denotes standard deviation; TTE, transthoracic echocardiography; TEE, transesophageal echocardiography; BP, biplane; 3D, three-dimensional. *P-value for correlation coefficient.

consequences $[7,25]$. At present, there is no gold standard for non-invasive assessment of AoA dimension, and available techniques include different echocardiographic modalities as well as MSCT and angiography. However, TEE is typically frequently used as it enables the annulus to be directly visualized. In the current study, in a cohort of 50 patients referred for evaluation prior to TAVI, we found that taking AoA measurements by 2DTTE leads to significant underestimation and wide limits of agreement, as compared with other imaging modalities. While this is in agreement with previously published data in this field $[12,26]$, it does challenge a recent report by Messika-Zeitoun et al. where no statistically significant difference was found between TTE and 2DTEE-based AoA measurements [13]. There are several possible explanations why AoA may be underestimated by 2DTTE. Apart from the aforementioned 2D orientation of the image plane, severe calcification and shadowing can make exact image interpretation and annulus measurements on TTE difficult. This limitation can be overcome using 3DTEE.

In patients undergoing TAVI with the Medtronic CoreValve System $^{\mathrm{TM}}$, a $26 \mathrm{~mm}$ prosthesis is recommended for a $20-23 \mathrm{~mm}$ annulus and a $29 \mathrm{~mm}$ prosthesis in a $23-27 \mathrm{~mm}$ annulus [19]. TEE is recommended if the number of cusps cannot be determined [20]. The current recommendations for the use of echocardiography in transcatheter intervention suggest that 2DTEE and/or 3DTEE are used in patients whose 2DTTE-based AoA measurements are uncertain. This is especially pertinent when measurements are near critical cut-offs and in patients whose AoA cannot be determined due to calcification extending from aortic valve to either septum or anterior mitral leaflet. However, using TEE as a reference method has been associated with favorable clinical results $[13,27]$, and TEE is accordingly the most widely used imaging modality for this purpose $[6,28]$.

In our study, a measured AoA diameter $<20 \mathrm{~mm}$ was found in $36 \%(n=18)$ of the patient population using 2DTTE, but only in $12 \%(n=6)$ based on 2DTEE and $4 \%$ $(\mathrm{n}=2)$ and $2 \%(\mathrm{n}=1)$ respectively, based on BP-mode and RT3DE images. This implies that a significant proportion of patients are in appropriately deemed to be unsuitable for TAVI when 2DTTE is used to measure AoA. Interestingly, in the conservatively managed arm of the PARTNER trial, mortality at 12 months was $51 \%$ with standard therapy compared to $31 \%$ with TAVI [29]. This demonstrates that the prognosis of patients that are wrongly declined TAVI is dismal and illustrates the potentially very large clinical implications of this finding.

Aortic annulus is described as a virtual ring formed by joining the basal attachments of the aortic cusps [9]. Several studies have shown that in many patients the aortic annulus is not circular but in fact oval in shape. This is likely to be the root cause behind the failure to measure AoA correctly in a single image plane $[13,15,26,30,31]$, and explains the superiority of $3 \mathrm{DE}$, which enables the larger coronal diameter of an ellipsoid AoA to be measured and not only the smaller sagittal.

We found good reproducibility in determination of AoA size with all echocardiographic modalities, the highest being with 3DTEE which has also been shown in other studies [12,31,32]. On the contrary, AoA measurements performed by $\mathrm{CT}$ has been demonstrated to have poor inter-observer variability [26]. While 3DTEE is widely used in this patient group, it requires post-processing at a dedicated workstation with appropriate software and training. Importantly, BP-mode and 3DTEE provided similar measurements (as evidenced by strong correlations) with similar inter-observer variability. Moreover, misclassification did not occur using BP-mode.

\section{Limitations}

This study has several limitations. A major limitation is the lack of independent reference method like MSCT. The biplane mode technique for assessment of aortic annulus size is limited in terms of not to be able to measure the coronal diameter of the annulus and therefore the annulus area. This might be important since prosthesis/annulus area mismatch assessed by 3DTEE has recently shown to predict the outcome of significant paravalvular leak post TAVI [33]. Lastly, our study is limited by its lack of clinical outcome data. 


\section{Conclusions}

TAVI is offered to a very rapidly growing group of patients with severe aortic stenosis. We conclude that multi-plane imaging using BP-mode enables a speedy measurement to be taken of AoA which is both robust and exact. Moreover, a considerable proportion of patients are misclassified by single plane measurements as unsuitable for TAVI which is unfortunate and may have major clinical implications. This issue deserves to be studied in a prospective design in future research in this field.

\section{Competing interests}

The authors declare that they have no competing interests.

\section{Authors' contributions}

KS initiated the study and included the patients and performed the image acquisitions together with MB. AS supervised the study and participated in the interpretation of the results and manuscript preparation. KS and AM performed measurements. KS and CdS performed statistical analysis of the manuscript and made all data conversions and plots. All authors read and approved the final manuscript.

Received: 17 November 2012 Accepted: 28 January 2013

Published: 30 January 2013

\section{References}

1. Nkomo VR, Gardin JM, Skelton TN, Gottdiener JS, Scott CG, Enriquez-Sarano M: Burden of valvular heart diseases. Lancet 2006, 368:1005-1011.

2. Lindroos M, Kupari M, Heikkilä J, Tilvis R: Prevalence of aortic valve abnormalities in the elderly: an echocardiographic study of a random population sample. J Am Coll Cardiol 1993, 21:1220-1225.

3. Bonow RO, Carabello BA, Kanu C, de Leon AC, Jr FDP, Freed MD, Gaasch WH, Lytle BW, Nishimura RA, O'Gara PT, O'Rourke RA, Otto CM, Shah PM, Shanewise JS, Smith SC Jr, Jacobs AK, Adams CD, Anderson JL, Antman EM, Faxon DP, Fuster V, Halperin JL, Hiratzka LF, Hunt SA, Lytle BW, Nishimura R, Page RL, Riegel B: ACC/AHA 2006 guidelines for the management of patients with valvular heart disease: a report of the American College of Cardiology/ American Heart Association Task Force on Practice Guidelines Writing Committee to Revise the 1998 Guidelines for the Management of Patients With Valvular Heart Disease. J Am Coll Cardiol 2006, 48:1-148.

4. Cribier A, Eltchaninoff H, Tron C, Bauer F, Agatiello C, Nercolini D, Tapiero S, Litzler PY, Bessou JP, Babaliaros V: Treatment of calcific aortic stenosis with the percutaneous heartvalve: Mid-term follow-up from the initial feasibility studies: The French experience. J Am Coll Cardiol 2006, 47:1214-1223.

5. Piazza N, Grube E, Gerckens U, den Heijer P, Linke A, Luha O, Ramondo A, Ussia G, Wenaweser P, Windecker S, Laborde JC, de Jaegere P, Serruys PW: Procedural and 30-day outcomes following transcatheter aortic valve implantation using the third generation (18 Fr) corevalve revalving system: Results from the multicentre, expanded evaluation registry 1year following CE mark approval. Euro Intervention 2008, 4:242-249.

6. Webb JG, Altwegg L, Boone RH, Cheung A, Ye J, Lichtenstein S, Lee M, Masson JB, Thompson C, Moss R, Carere R, Munt B, Nietlispach F, Humphries K: Transcatheter aortic valve implantation: Impact on clinical and valverelated outcomes. Circulation 2009, 119:3009-3016.

7. Chin D: Echocardiography for transcatheter aortic valve implantation. Eur J Echocardiogr 2009, 10:i21-i29.

8. Jilaihawi H, Chin D, Spyt T, Jeilan M, Vasa-Nicotera M, Bence J, Logtens E, Kovac $\mathrm{J}$ : Prosthesis-patient mismatch after transcatheter aortic valve implantation with the Medtronic-Corevalve bioprosthesis. Eur Heart J 2010, 31:857-864.

9. Kalavrouziotis D, Rodés-Cabau J, Bagur R, Doyle D, De Larochellière R, Pibarot $P$, Dumont $\mathrm{E}$ : Transcatheter aortic valve implantation in patients with severe aortic stenosis and small aortic annulus. J Am Coll Cardiol 2011, 58:1016-1024.

10. Tzikas A, Schultz CJ, Piazza N, Moelker A, Van Mieghem NM, Nuis RJ, van Geuns RJ, Geleijnse ML, Serruys PW, de Jaegere PP: Assessment of the Aortic Annulus by Multislice Computed Tomography, Contrast Aortography, and Trans-Thoracic Echocardiography in Patients Referred for Transcatheter Aortic Valve Implantation. Catheter Cardiovasc Interv 2011, 77:868-875.
11. Gurvitch R, Webb JG, Yuan R, Johnson M, Hague C, Willson AB, Toggweiler S, Wood DA, Ye J, Moss R, Thompson CR, Achenbach S, Min JK, Labounty TM, Cury R, Leipsic J: Aortic annulus diameter determination by multidetector computed tomography: reproducibility, applicability, and implications for transcatheter aortic valve implantation. JACC CardiovasC Imaging 2011, 4:1235-1245.

12. Altiok E, Koos R, Schröder J, Brehmer $K$, Hamada S, Becker M, Mahnken AH, Almalla M, Dohmen G, Autschbach R, Marx N, Hoffmann R: Comparison of two-dimensional and three-dimensional imaging techniques for measurement of aortic annulus diameters before transcatheter aortic valve implantation. Heart 2011, 97:1578-1584.

13. Messika-Zeitoun D, Serfaty JM, Brochet E, Ducroca G, Lepage L, Detaint D, Hyafil F, Himbert D, Pasi N, Laissy JP, lung B, Vahanian A: Multimodal assessment of the aortic annulus diameter: implications for transcatheter aortic valve implantation. J Am Coll Cardiol 2010, 55:186-194.

14. Delgado V, Ng AC, van de Veire NR, van der Kley F, Schuijf JD, Tops LF, de Weger A, Tavilla G, de Roos A, Kroft LJ, Schalij MJ, Bax JJ: Transcatheter aortic valve implantation: role of multi-detector row computed tomography to evaluate prosthesis positioning and deployment in relation to valve function. Eur Heart J 2010, 31:1114-1123.

15. Ng AC, Delgado V, van der Kley F, Shanks M, van de Veire NR, Bertini M, Nucifora G, van Bommel RJ, Tops LF, de Weger A, Tavilla G, de Roos A, Kroft LJ, Leung DY, Schuijf J, Schalij MJ, Bax JJ: Comparison of aortic root dimensions and geometries before and after transcatheter aortic valve implantation by 2- and 3-dimensional transesophageal echocardiography and multislice computed tomography. Circ Cardiovasc Imaging 2010, 3:94-102.

16. Schoenhagen $P$, Numburi U, Halliburton SS, Aulbach $P$, von Roden M, Desai MY, Rodriguez LL, Kapadia SR, Tuzcu EM, Lytle BW: Three-dimensional imaging in the context of minimally invasive and transcatheter cardiovascular interventions using multi-detector computed tomography: from pre-operative planning to intra-operative guidance. Eur Heart J 2010, 31:2727-2740.

17. Dashkevich A, Blanke P, Siepe M, Pache G, Langer M, Schlensak C, Beyersdorf F: Preoperative Assessment of Aortic Annulus Dimensions: Comparison of Noninvasive and Intraoperative Measurement. Ann Thorac Surg 2011, 91:709-714.

18. Husser $\mathrm{O}$, Rauch S, Endemann DH, Resch M, Nunez J, Bodi V, Hilker M, Schmid C, Riegger GA, Luchner A, Hengstenberg C: Impact of threedimensional transesophageal echocardiography on prosthesis sizing for transcatheter aortic valve implantation. Catheter Cardiovasc Interv 2012, 14. Epub ahead of print.

19. Zamorano JL, Badano LP, Bruce C, Chan KL, Gonçalves A, Hahn RT, Keane MG La Canna G, Monaghan MJ, Nihoyannopoulos P, Silvestry FE, Vanoverschelde JL, Gillam LD, Vahanian A, Di Bello V, Buck T: Document Reviewers: EAE/ASE recommendations for the use of echocardiography in new transcatheter interventions for valvular heart disease. Eur Heart J 2011, 12:557-584.

20. Baumgartner H, Hung J, Bermejo J, Chambers JB, Evangelista A, Griffin BP, lung B, Otto CM, Pellikka PA, Quiñones M: Echocardiographic assessment of valve stenosis: EAE/ASE recommendations for clinical practice. American Society of Echocardiography; European Association of Echocardiography. J Am Soc Echocardiogr 2009, 22:1-23.

21. Lancellotti P, Tribouilloy C, Hagendorff A, Moura L, Popescu BA, Agricola E, Monin JL, Pierard LA, Badano L, Zamorano JL: European Association of Echocardiography position papers for the assessment of valvular regurgitation. Part 1: aortic and pulmonary regurgitation (native valve disease) on behalf of the European Association of Echocardiography. Eur J Echocardiogr 2010, 11:223-244.

22. Evangelista A, Flachskampf FA, Erbel R, Antonini-Canterin F, Vlachopoulos C, Rocchi G, Sicari R, Nihoyannopoulos P, Zamorano J: Echocardiography in aortic diseases: EAE recommendations for clinical practice. Eur $J$ Echocardiogr 2010, 11:645-658.

23. Bland JM, Altman DG: Statistical methods for assessing agreement between two methods of clinical measurement. Lancet 1986, 1:307-10.

24. Dahlberg G: Statistical methods for medical and biological students. New York: Interscience Publications; 1940

25. Abdel-Wahab M, Zahn R, Horack M, Gerckens U, Schuler G, Sievert H, Eggebrecht $\mathrm{H}$, Senges J, Richardt G: Aortic regurgitation after transcatheter aortic valve implantation: incidence and early outcome. Results from the German transcatheter aortic valve interventions registry. Eur Heart J 2011, 11:899-906. 
26. Wood DA, Tops LF, Mayo JR, Pasupati S, Schalij MJ, Humphries K, Lee M, A Ali A, Munt B, Moss R, Thompson CR, Bax JJ, Webb JG: Role of multislice computed tomography in transcatheter aortic valve replacement. Am J Cardiol 2009, 103:1295-1301.

27. Hutter A, Opitz A, Bleiziffer S, Ruge H, Hettich I, Mazzitelli D, Will A, Tassani $P$, Bauernschmitt $R$, Lange $R$ : Aortic annulus evaluation in transcatheter aortic valve implantation. Catheter Cardiovasc Interv 2010, 76:1009-19.

28. Moss RR, Ivens E, Pasupati S, Humphries K, Thompson CR, Munt B, Sinhal A, Webb JG: Role of Echocardiography in Percutaneous Aortic Valve Implantation. JACC Cardiovasc Imaging 2008, 1:15-24.

29. Leon MB, Smith CR, Mack M, Miller DC, Moses JW, Svensson LG, Tuzcu EM, Webb JG, Fontana GP, Makkar RR, Brown DL, Block PC, Guyton RA, Pichard AD, Bavaria JE, Herrmann HC, Douglas PS, Petersen JL, Akin JJ, Anderson WN, Wang D, Pocock ST: Transcatheter aortic-valve implantation for aortic stenosis in patients who cannot undergo surgery; PARTNER Trial Investigators. N Engl J Med 2010, 363:1597-1607.

30. Piazza N, de Jaegere P, Schultz C, Becker AE, Serruys PW, Anderson RH: Anatomy of the aortic valvar complex and its implications for transcatheter implantation of the aortic valve. Circ Cardiovasc Intervent 2008, 1:74-81.

31. Tops LF, Wood DA, Delgado V, Schuijf JD, Mayo JR, Pasupati S, Lamers FP, van der Wall EE, Schalij MJ, Webb JG, Bax JJ: Noninvasive evaluation of the aortic root with multislice computed tomography implications for transcatheter aortic valve replacement. JACC Cardiovasc Imaging 2008, 1:321-330.

32. Jánosi RA, Kahlert P, Plicht $B$, Wendt $D$, Eggebrecht $H$, Erbel $R$, Buck $T$ : Measurement of the aortic annulus size by real-time three-dimensional transesophageal echocardiography. Minim Invasive Ther Allied Technol 2011, 20:85-94.

33. Santos N, de Agustín JA, Almería C, Gonçalves A, Marcos-Alberca P, Fernández-Golfín C, García E, Hernández-Antolín R, de Isla LP, Macaya C, Zamorano J: Prosthesis/annulus discongruence assessed by threedimensional transoesophageal echocardiography: A predictor of significant paravalvular aortic regurgitation after transcatheter aortic valve implantation. Eur Heart J Cardiovasc Imaging 2012, 17:931-937.

doi:10.1186/1476-7120-11-5

Cite this article as: Shahgaldi et al:: Transesophageal echocardiography measurements of aortic annulus diameter using biplane mode in patients undergoing transcatheter aortic valve implantation.

Cardiovascular Ultrasound 2013 11:5.

\section{Submit your next manuscript to BioMed Central and take full advantage of:}

- Convenient online submission

- Thorough peer review

- No space constraints or color figure charges

- Immediate publication on acceptance

- Inclusion in PubMed, CAS, Scopus and Google Scholar

- Research which is freely available for redistribution 